Session 1268

\title{
Design and Test Project in a Statics Course
}

\author{
Dr. Martin Pike \\ Purdue University Programs at Kokomo
}

\begin{abstract}
$\underline{\text { Abstract }}$
The design experience is very important in all technical areas. Recent trends have pushed design experiences as early in the curriculum as possible. Often, the first design experiences are a single pass "paper" design without any realistic testing and design evaluation. This paper relates the experience of incorporating a design/build/test/redesign project into a Statics course. This is the first course in the Purdue University Mechanical Engineering Technology program where students are being exposed to the design experience. The goal of the project was to expose the students to the full design cycle and to verify that the analysis methods learned in class really do predict the structure's behavior. The project was a group effort to design and build a truss structure given exterior dimension constraints, load point constraints and a provided pack of materials. The student groups were to design the truss to maximize a score determined mainly as a function of the load to failure divided by the structure's weight. On a prearranged date, all trusses were loaded to failure in a tensile test machine. Afterwards, the class as a whole discussed the merits and shortcomings of each of the designs tested, how and why they failed as they did, and how a better tress might be built. This paper relates the particulars of the project definition, how the project was managed, success of the design project in meeting the goals, and students' reactions to the project.
\end{abstract}

\section{Introduction}

The design experience is very important in the engineering and technology fields. To maximize the exposure to the design experience, the curriculum has been altered to introduce design as early as possible at many schools. At Purdue University in the Mechanical Engineering Technology (MET) curriculum, the statics course offered in the second semester of the freshman year is the first feasible course that mechanical design can be introduced. For three semesters a design project has been assigned as part of this course at the Kokomo regional campus as one way to expose the students to design. The project requires the students to apply basic statics concepts to design, build and test a truss structure that meets given criteria of size and available materials. The project was designed to be a practical build, test project, and redesign project and not only a "paper design" for three reasons. First, without the testing aspect of the project the idea of redesign or design alteration to take into account testing results would be meaningless. This, to the author, is an important part of the design process since very few designs are successful in the first iteration. Second, in the testing process the students should gain a better understanding of statics and find out that the calculations really do predict the behavior of the structure. Last, with a build and test component, the students in the MET program were more interested in doing a good job resulting in a moderately competitive atmosphere among the design groups. 


\section{The Design Project}

The design project required the students to design a truss that would support a load at mid span, be supported at the outer ends of the truss, and fail at a predetermined load. The span of the truss was thirty inches with an allowable maximum height of six inches and thickness of one inch. These dimensions were determined by the size of the tensile test machine we had available to use, a reasonable size for probability yet not so small that craftsmanship in the building would have a large impact. The students were to determine the load of failure in the process of designing their truss. The load at failure would be different for each student group since the students were allowed to use all or any part of the pack of materials supplied. The "success" of the truss was to be a function of the efficiency of the structure: load carried divided by the structure's weight. This allowed the students the freedom to build a light, simple structure that would carry a relatively small load, a massive and complex structure that would carry a large load, or any possibility in between. Since fasteners overwhelmed the weight of the other structural members, the weight of the fasteners was subtracted from the total weight to determine the truss structures' weight for all efficiency calculations. The materials supplied were a one 12 foot long, 1/2 inch OD, 0.035 inch wall thickness, 6061-T6 aluminum tube, a 12 inch by 24 inch 6061 aluminum sheet of 0.063 inch thickness, and 100- 1/8 inch pop style rivets (first time project tried) or 50-3/16 inch cotter pins. The students were given the tensile strength of the tube and a chart of the compressive strength of the tube for varying lengths. They were also told that the truss will fail in one of two ways: either the tube would buckle in compression or the tube would break at the drilled holes in tension.

The students were required to work in pairs or groups of three where each member of the group was to design a truss and the group would choose what they thought was the best design to build and test. (Class sizes ranged from 12 to 18 students. ) Group effort was required for two reasons. First, the students need exposure to group efforts, the management of the group and group dynamics. Often, the students found that the quality of the group's results were far superior than what one lone person could produce. Second, small groups allowed for many different trusses to test, but many fewer and cheaper than every person doing an individual project.

The project definition also specified the grading of the project. The grade for the project was based equally on two aspects: the "efficiency" of the structure as defined above and the relative accuracy of the predicted failure load. The students were allowed to choose a failure load estimate that was anywhere within ten percent of the calculated failure load. This allowed for the students to take into account the craftsmanship of the construction and its impact on the truss' strengths.

\section{$\underline{\text { Testing and Redesign }}$}

Before the trusses were tested, each group was required to provide a written report containing the analysis of the design and the failure load calculation and estimate. The trusses were all weighed then tested until failure in a tensile test machine fitted with a load. Failure was defined as either the rupture of any part of the structure or visible deflection of the structure with constant or decreasing applied load. After all the trusses had been tested the "efficiency" of each structure was calculated and placed on an overhead with the predicted and tested failure loads. Since all the students in the class had witnessed the tests the instructor started a discussion of the merits of each structure and why some did better than others. This led into a discussion of what each group would do differently if they were to redesign the truss. Also discussed were any surprises that happened. Included were questions such as: Why did the structures fail and at the load they did? How close were the failure estimates to the actual failure loads? 


\section{$\underline{\text { Result of Three Class Sections }}$}

This project has been assigned to three classes in three separate semesters. The first group used the pop rivets. The results for the first group were disappointing because all the failures occurred due to the rivets failing by pulling out. The following two classes used cotter pins with much better success. The students were in general surprised that their calculated failure loads were fairly close and usually lower than the actual failure load. Failure loads ranged from about $80 \%$ to over $150^{\circ} \mathrm{A}$ of expected strength with most failures within $15 \%$ of the expected strength of the truss. The students were eager to redesign the trusses but since the project was due at the end of the term we did not have time to do this. Many students felt that the project helped their understanding of statics and was well worth the time and effort needed to complete it.

From an instructor's point of view, the project during the last two terms was very successful. In general, all the goals of the project were met. The students gained a good understanding of the design process, improved their group interactive skills, and saw a practical application of the static analysis we have been doing in class.

\section{$\underline{\text { Future Projects }}$}

For future terms the author is considering two possible changes to the design project. The first change that is desirable is to schedule the project earlier in the term to allow the students to actually do a redesign and test the redesigned truss. The first test would have to be done in private with each group so that they are not overly influenced by other groups' testing results. The intent would be for the students to refine their design, not to remake the most successful design of the class. The problem with this change is that two packets of material per group would have to be provided, doubling the ten dollar per group cost for the project. A second potential change is to use square steel tube that is welded together. The fastening technique used has a great influence on the success of the project. Pop rivets and cotter pins were used to allow the students to easily cut and assemble their own truss without the need for special tools. Any drilling weakens the tubing and biases the failure to occur at the weakened area. Fasteners and gussets were for some students difficult to align and produce a well made truss. This change to welded joints would require professional assembly and require more advanced scheduling of the project to allow all the groups to have their projects assembled. However, welded joints would more closely mimic current industrial practices and produce professional craftsmanship in each truss.

\section{$\underline{\text { Conclusions }}$}

In general, the author is pleased with the success of the truss design project. The students generally enjoyed building and testing the projects. They felt that they gained from the experience. All the goals of introducing design, test and considering redesign were met. The students seem to understand the concepts of statics better as well as have an appreciation that the structural analysis does have some basis in reality.

MARTIN PIKE is an Associate Professor of Mechanical Engineering Technology at Purdue University at Kokomo. He has over thirteen years of teaching experience in addition to six years experience in industry as a design and development engineer. He earned a BSME in 1977, an MSE in 1981 and Dr. Sci. in Engineering in 1990. 